\title{
QUESTIONANDO AS DELIMITAÇÕES CARTOGRÁFICAS DA CULTURA
}

\author{
Leonardo Luiz Silveira da Silva \\ Instituto Federal de Educação, Ciência e Tecnologia do Norte de Minas Gerais, Salinas, MG, Brasil \\ leonardo.silveira@ifnmg.edu.br \\ Alfredo Costa
Instituto Federal de Educação, Ciência e Tecnologia do Norte de Minas Gerais, Almenara, MG, Brasil
alfredo.costa@ifnmg.edu.br
}

\begin{abstract}
RESUMO
Partindo da reflexão sobre a natureza híbrida, permeável e dinâmica da cultura, este artigo traça uma reflexão sobre as possibilidades de sua representação cartográfica. Declarando a cultura como uma entidade intangível ou mesmo "uma imaginação coletiva" e tendo como sustento teórico a argumentação de Benedict Anderson acerca da ideia de nação, analisa-se a hipótese de que a delimitação de elementos culturais ou da cultura propriamente dita é equivocado. Para tanto, parte do pressuposto que as representações culturais possuem pretensões totalizantes, não passando, contudo, de expressões individuais ou de coletividades precisas. $\mathrm{O}$ artigo apresenta ainda os mapas mentais como formas de superar os dilemas da representação de elementos culturais, desde que os mesmos abandonem a pretensão da totalidade e se apresentem como expressões da experiência individual ou de grupos bem delimitados. Neste particular, os mapas mentais não devem aspirar se constituírem como representações da cultura propriamente dita, que são essencialmente totalizantes e incompatíveis com as interpretações individuais ou de grupos restritos.
\end{abstract}

Palavras-chave: Cultura. Representação Cartográfica. Mapas Mentais.

\section{QUESTIONING THE CARTOGRAPHIC DELIMITATIONS OF CULTURE}

\begin{abstract}
Starting from the reflection on the hybrid, permeable and dynamic nature of culture, this article traces a reflection on the possibilities of its cartographic representation. Assuming culture as an intangible entity, or even, "a collective imagination," and based on Benedict Anderson's argument about the idea of nation, the hypothesis is that the delimitation of cultural elements or of the culture itself is wrong For this, this study assumes that cultural representations have totalizing pretensions, but are only individual expressions or expressions of specific collectivities. The article also presents mental maps as ways of overcoming the dilemmas of the representation of cultural elements, as long as they abandon the pretension of totality and present themselves as expressions of individual experiences or well-defined groups. Therefore, mental maps should not be intended as representations of the culture itself. Even their synthesis would be essentially totalizing and incompatible with individual interpretations or restricted groups.
\end{abstract}

Keywords: Culture. Cartographic Representation. Mental Maps.

\section{INTRODUÇÃO}

A hibridez, porosidade e dinamismo são apanágios da cultura. Assim, a concretização de regionalizações culturais se parece inadequada, à medida que os seus limites não seriam realizáveis (SILVA e COSTA, 2018). Esta noção tem servido à crítica de autores que pouco relativizam o binômio cultura e espaço, como se registrou no embate entre Edward Saïd e Samuel Huntington. O primeiro acusou o segundo de ignorar as características marcantes da cultura defendidas pela moderna antropologia ao propor um mundo dividido em áreas supostamente homogêneas do ponto de vista cultural (SAïD, 2007), na ocasião da conhecida tese do choque das 
civilizações (HUNTINGTON, 1997). Ainda que sejam pertinentes estas reflexões apresentadas, algumas questões estimulam 0 avanço deste debate. A primeira questão refere-se à produção de mapas mentais. Estes, algumas vezes, são referidos como representações das experiências sensoriais humanas (TUAN, 1975a), podendo, desta forma, refletir os aspectos identitários dos seus autores, possibilitando, até mesmo, a inferência sobre elementos culturais. Afinal, os mapas mentais são arquitetados pela cosmovisão dos seus autores ou de grupos de indivíduos, sendo, portanto, construídos a partir de contextos culturais. Penetrando de forma elusiva nos limites semânticos entre cultura e identidade e esgueirando-se entre a realidade concreta e imaterial, os mapas mentais seriam exceções mediante a crítica às regionalizações culturais? E ainda, estariam perdoados por cometerem o sacrilégio de ousarem estabelecer limites naquilo que é intangível?

A segunda questão baseia-se nos diferentes entendimentos quanto à cultura: seria a mesma uma realidade material, um fato concreto passível de ser mapeável? Ou seria a cultura fruto da imaginação que ganha concretude por intermédio de um processo de construção político-social que une, por sua vez, determinadas intersubjetividades em um objetivo comum? É importante sinalizar, de antemão, que tal premissa poderia aproximar o status da cultura daquele desfrutado pela nação, no sentido trazido por Bennedict Anderson (2008): uma comunidade imaginada. Assim sendo, seria a cultura mapeável?

A reflexão acerca destes questionamentos conduzem a um objetivo maior deste artigo, que é propor uma reflexão sobre a natureza dos contrassensos existentes entre as representações espaciais da cultura. Para tanto, cabe uma reflexão sobre a epistemologia da representação espacial da cultura, que, muitas vezes, é representada banalmente em diversas cartografias, em construções que ignoram pressupostos elementares da antropologia. É justamente por intermédio desta negligência que ganham vida os contrassensos. $O$ artigo em questão não é uma revisão bibliográfica. Utiliza-se, contudo, de reflexões presentes em vários campos das humanidades para indutivamente construir o arcabouço teórico que problematizará a existência dos contrassensos que residem na representação espacial da cultura.

\section{A IDENTIDADE, A EXPERIÊNCIA HUMANA E AS INTERSUBJETIVIDADES}

Partindo dos pressupostos da moderna antropologia e versando, portanto, através do escopo de certas abordagens da Geografia Humanista, considerou-se que as identidades, assim como as culturas, são essencialmente híbridas e inter-relacionadas, sendo construídas diacronicamente pela experiência humana. Nesta discussão, Gupta e Ferguson (1992) lançam as perguntas: a quais lugares as culturas híbridas da pós-colonialidade pertencem? E ainda: o entendimento do caráter híbrido da cultura desestabiliza a noção de que nações e a cultura propriamente dita são isomórficas? Estas são questões que apoiam o entendimento dos contrassensos da delimitação geográfica da cultura.

A experiência humana é um termo abrangente para os vários modos pelos quais uma pessoa conhece seu mundo. Por meio dos sentidos, há a sensação de se estar ativamente explorando 0 mundo além dos significados a ele pré-atribuídos e, por consequência, de conhece-lo objetivamente . No entanto, as particularidades que envolvem as experiências fazem que estas, colocadas lado a lado, proporcionem um mergulho no universo da intersubjetividade. A experiência humana é condicionada pelos sentidos que podem ser ativos ou passivos: as sensações do modo passivo estão trancadas dentro dos indivíduos e não possuem existência pública. Tudo o que se vê pode ser apresentado em fotos e em mapas, aos quais todos tem acesso. Por outro lado, a qualidade especial de uma fragrância, gosto ou toque não pode ser projetada em um palco público a não ser por meios pictóricos e linguísticos. Os artistas são admirados porque, até certo ponto, podem objetivar sentimentos íntimos em uma pintura, escultura ou em palavras. Poucas pessoas têm essa habilidade (TUAN, 1975b; PORTEOUS, 1985; PORTEOUS e MASTIN, 1985). Dentre esses sentidos passivos destacam-se o paladar, o olfato e o tato.

Há ainda o caráter fugaz e caótico da experiência: usa-se palavras, gestos e até mesmo constrói-se artefatos também para dar uma aparência de duração e coerência nos eventos que confrontados. Um evento raramente é capaz de falar de forma inequívoca por si mesmo. Sua importância depende, pelo menos em parte, do apoio de palavras e gestos. Assim, um artesão, depois de dar o polimento final em uma jarra, tende a chamar pessoas para admirá-la, o que atribuirá uma pluralidade de significações no seu trabalho (TUAN, 1980a) e, ao mesmo tempo, conferirá ao 
artefato um leque de significados e impressões que dão a dimensão da pluralidade intersubjetiva. É importante destacar que a intersubjetividade da percepção humana construída por intermédio da experiência não se trata de uma exceção: é uma regra.

Por outro lado, a ausência de experiência pode nos levar a um terreno ainda mais caótico. Geralmente é sabido que pode-se contar com um determinado parente ou mesmo um vizinho quando em uma dada situação de dificuldade. Um estranho, por sua vez, pode despertar os sentimentos mais ambíguos: de alguém que ameaça o nosso lar a um salvador. Pessoas em várias partes do mundo, em suas cosmologias específicas, têm lendas que mencionam a existência de seres superiores e bondosos além do seu próprio mundo conhecido (TUAN, 1986). Este sentimento parece existir mesmo em sociedades com maior experiência com conceitos antropológicos. Os europeus do século XVIII e XIX utilizavam o conceito de luz e sombras para antagonizar e estereotipar povos ao redor do mundo. Na literatura, o Coração das Trevas de Joseph Conrad (2010) era a África Equatorial. Na pintura, "O Progresso Americano" de John Gast (1872) antagoniza a luz e as sombras, expressando a marcha para o oeste norte-americano, de forma a indicar que as sombras dominavam a área não colonizada, povoada por povos nativos, enquanto que as luzes iluminam o leste atlântico, já devidamente colonizado (Figura 1).

É importante considerarmos que a ausência de experiência também produz expressões intersubjetivas. O pré-julgamento sobre aquilo que é desconhecido advém de uma lógica dedutiva guiada por outras experiências. Por isso, mesmo no período inicial da colonização americana, visões tão distintas acerca do nativo americano como as trazidas pelo frade Bartolomé de Las Casas, em um extremo, e o filósofo Juan Ginés de Sepúlveda, em outro, encontravam lugar (WALLERSTEIN, 2007). O embate entre estes dois partícipes da colonização americana apontou para a pluralidade da percepção do lugar do nativo na mentalidade do colonizador europeu, à medida que o purismo etnocêntrico de Sepúlveda era desafiado pelos lampejos de alteridade de Las Casas.

Figura 1 - Gast, John. O Progresso Americano, 1872. Litografia em cores, 37,6 x $49 \mathrm{~cm}$. Library of Congress Prints and Photographs Division, Washington, DC.

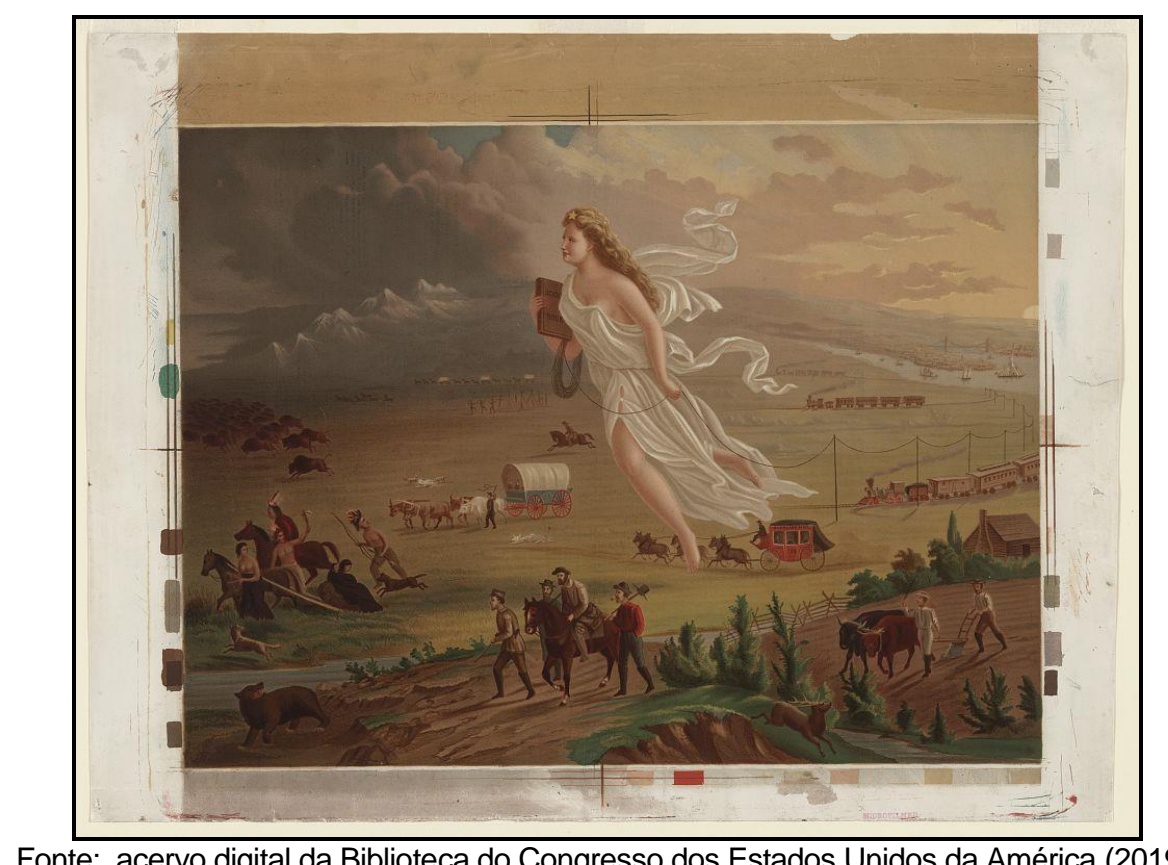

Fonte: acervo digital da Biblioteca do Congresso dos Estados Unidos da América (2019).

As identidades constituem-se sempre como um processo problemático de acesso à totalidade. Tratar-se-iam de parcelas da totalidade, não passando, portanto, em sua descrição mais minuciosa, de um esboço. A representação da identidade é sempre espacialmente fendida: reúne experiências 
constitutivas advindas de diferentes porções do espaço. É, também, temporalmente adiada: representa tempos que são verdadeiramente retalhos diacrônicos. Assim, uma descrição de identidade não pode se constituir, por exemplo, como o retrato de uma nação ou como o relato de uma cultura (BHABHA, 2013). Nesse sentido, a ingênua pretensão do domínio da realidade passa, necessariamente, pela profunda negação do exercício da alteridade.

Ademais, Maurice Halbwachs ensina que as identidades carregam memórias individuais e coletivas. Assim, todo indivíduo traria estas duas memórias e, conforme participe de uma ou de outra, adotaria atitudes muito diferentes e mesmo contrárias: de um lado, é no quadro de sua personalidade ou de sua vida pessoal que viriam tomar lugar suas lembranças; do outro, seria capaz, em alguns momentos, de se comportar simplesmente como membro de um grupo que contribui para evocar e manter lembranças impessoais, à medida que estas interessam ao grupo (HALBWACHS, 1990).

Levando-se em conta a multiplicidade de arranjos identitários é que consideramos a possibilidade de uma grande diversidade de percepções ambientais. Yi-Fu Tuan (1980b) refere-se a uma passagem muito didática contida na obra clássica dos estudos antropológicos "Os Nuer", de EvansPritchard: "ninguém convence aos Nuer que aquela paisagem duramente árida na qual habitam não se trata do melhor lugar do mundo para se viver". Certamente as preferências paisagísticas dos Nuer não são idênticas. Contudo, o sentimento passado pela pintura Le pays de la soif do francês Eugène Fromentin (1820-1876) talvez pudesse ser interpretado por parcela do povo Nuer como histeria ou exagero europeu (Figura 2). A tela em questão retrata a Argélia sob ocupação francesa, sendo apresentada como uma barreira ou ameaça à vida (HEFFERNAN, 1991).

As distintas impressões sobre o deserto, entre nativos e colonizadores, apresentam de forma inequívoca a força do deslocamento identitário e mesmo das impressões estereotipadas. Por esta razão, provavelmente, Homy Bhabha referiu-se às identidades como um processo problemático de acesso à totalidade: qual seria a totalidade paisagística do deserto do Saara? Uma visão mais afetuosa e consolidada no corpo cultural de certos povos nativos saarauís? Ou um ambiente topofóbico (TUAN, 2005) como descrição intersubjetiva dominante do europeu novecentista?

Figura 2 - Fromentin, Eugène. Le pays de la soif, 1820-1876. Óleo sobre tela, 103 x 143,2 cm. Musee d'Orsay, Paris.

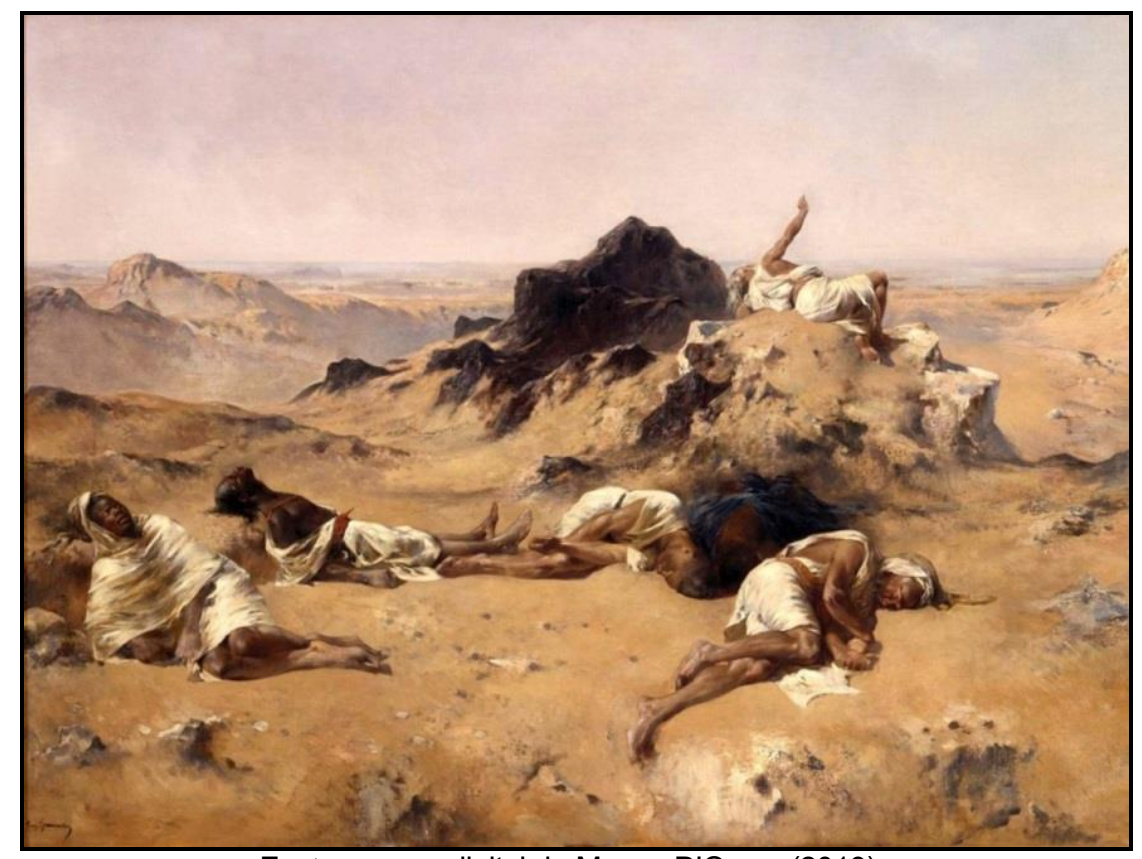

Fonte: acervo digital do Museu D’Orsay (2019) . 


\section{CULTURA E ESPAÇO}

A cultura é constituída de realidades e signos que foram inventados para descrevê-la, dominá-la e verbalizá-la. Carrega, portanto, uma dimensão simbólica. Gestos repetidos em público assumem novas significações. Transformam-se em rituais e criam, para aqueles que os praticam ou que os assistem, um sentimento de comunidade compartilhada (CLAVAL, 2001). Para que membros de uma sociedade disponham de conhecimentos geográficos satisfatórios em matéria de orientação, batizam terrenos e cobrem os espaços conhecidos com nomes de lugares: as toponímias (CLAVAL, 2011). Fala-se, também, de regionímias (os Alpes, a Savoia, a Dauphiné, a região de Lyon). Tanto as toponímias ou as regionímias podem ter a sua dimensão georreferenciada e, assumindo o status de espaços administrativos, tornam-se territórios. Contudo, nem sempre o espaço culturalmente percebido por um certo conjunto de pessoas condiz com a sólida construção georreferenciada do seu território, mesmo que este tenha se projetado como a representação espacial da cultura em questão.

Estas inconsistências encontram explicação no pressuposto inicial na abordagem que se propõe no artigo: a crença na estrutura híbrida da cultura e das identidades, seguramente amparada em vasta bibliografia, com destaque aos pensadores que foram enquadrados na corrente pós-colonial. Destacam-se, neste particular, Edward Saïd (2007, 2011), Terry Eagleton (2011), Stuart Hall (2013) e Homy Bhabha (2013). Particularmente interessado nos efeitos culturais das migrações caribenhas, Hall (2013) refletiu sobre a experiência de barbadianos no Reino Unido, concluindo que, se por um lado não apagaram sua barbadianidade [barbadianess], por outro, não construíram uma identidade inglesa. Por esta razão parece adequado relativizar a perspectiva de que os Estados-nação impõem fronteiras rígidas dentre as quais se espera que as culturas floresçam. Outros acreditam ainda que os limites desempenham um papel proeminente e até mesmo determinístico ao que tange à construção do discurso identitário contemporâneo (Newman, 2006).

Defende-se aqui a hipótese de que, considerando a essência da cultura, a mesma não é passível de ser delimitada. Espera-se que a cultura seja um constructo coletivo. Se as identidades expressam individualidades, espera-se que as culturas expressem consolidações coletivas. Acreditar na rigidez dos limites para a determinação das culturas trata-se de crer no engodo ou agarrar-se em uma crença que não se cumpre no primado da razão. Não só porque as experiências humanas muitas vezes ignoram os limites estatais, mas, principalmente, pela natureza híbrida das culturas. Estas características lançam-nos dúvidas sobre a possibilidade de considerarmos manifestações culturais ou a própria cultura como algo passível de ser regionalizado (SILVA e COSTA, 2018).

\section{COMO A CULTURA É REPRESENTADA}

As regionalizações culturais são, na verdade, propostas de compartimentação espaciais que abordam temas que podem se apresentar de forma bastante variada. O conjunto de temáticas pode ser hierarquizado em temas que variam de maior grau de especificidade até o maior grau de generalização. No topo desta hierarquia está a própria representação da "cultura", ainda que neste caso a proposição de recorte regional possa apresentar de forma mal definida os critérios para o estabelecimento dos limites e, portanto, das próprias unidades regionais. Em outro extremo hierárquico se enquadrariam temáticas como "gosto musical" ou até mesmo a posição quanto a temas como a "legalidade do aborto" ou a "aprovação do casamento de pessoas do mesmo sexo" (SILVA e COSTA, 2018). O Quadro 1 apresenta alguns temas culturais hierarquizados do maior ao menor patamar de generalização. 
Quadro 1 - Hierarquização de alguns temas culturais.

\begin{tabular}{|c|c|}
\hline Tema da regionalização & \multirow[b]{2}{*}{ + Generalização } \\
\hline $\begin{array}{l}\text { A cultura propriamente dita (a "brasileira", a } \\
\text { "baiana", a "sul-americana"). }\end{array}$ & \\
\hline $\begin{array}{c}\text { Tipologias de danças, línguas, religiões, culinárias } \\
\text { ou vestimentas, etc. }\end{array}$ & \\
\hline $\begin{array}{l}\text { Hora de acordar ou de dormir, gosto musical, força } \\
\text { da tradição rural, horas percebidas como } \\
\text { adequadas para a ocupação e para o ócio, } \\
\text { posicionamento em relação ao aborto e ao } \\
\text { casamento de pessoas do mesmo sexo, etc. }\end{array}$ & + Especificidade \\
\hline
\end{tabular}

Fonte: SILVA e COSTA (2018, p. 235).

As regionalizações com temas culturais mais específicos não parecem adequadas para representarem a coletividade, sobretudo quando considera-se o pressuposto pós-colonial da natureza híbrida das culturas. Afinal, é este o pressuposto que nos permite ver que uma cultura supostamente monolítica não passa de um mosaico de identidades (Figura 3). As investigações e representações que ousam abordar temáticas culturais de elevado grau de especificidade parecem mais sérias quando investigam o indivíduo e evitam a estereotipação de imagens coletivas (Figura 4). 
Figura 3 - Mosaico de representações cartográficas que apresentam a cultura de maneira monolítica.

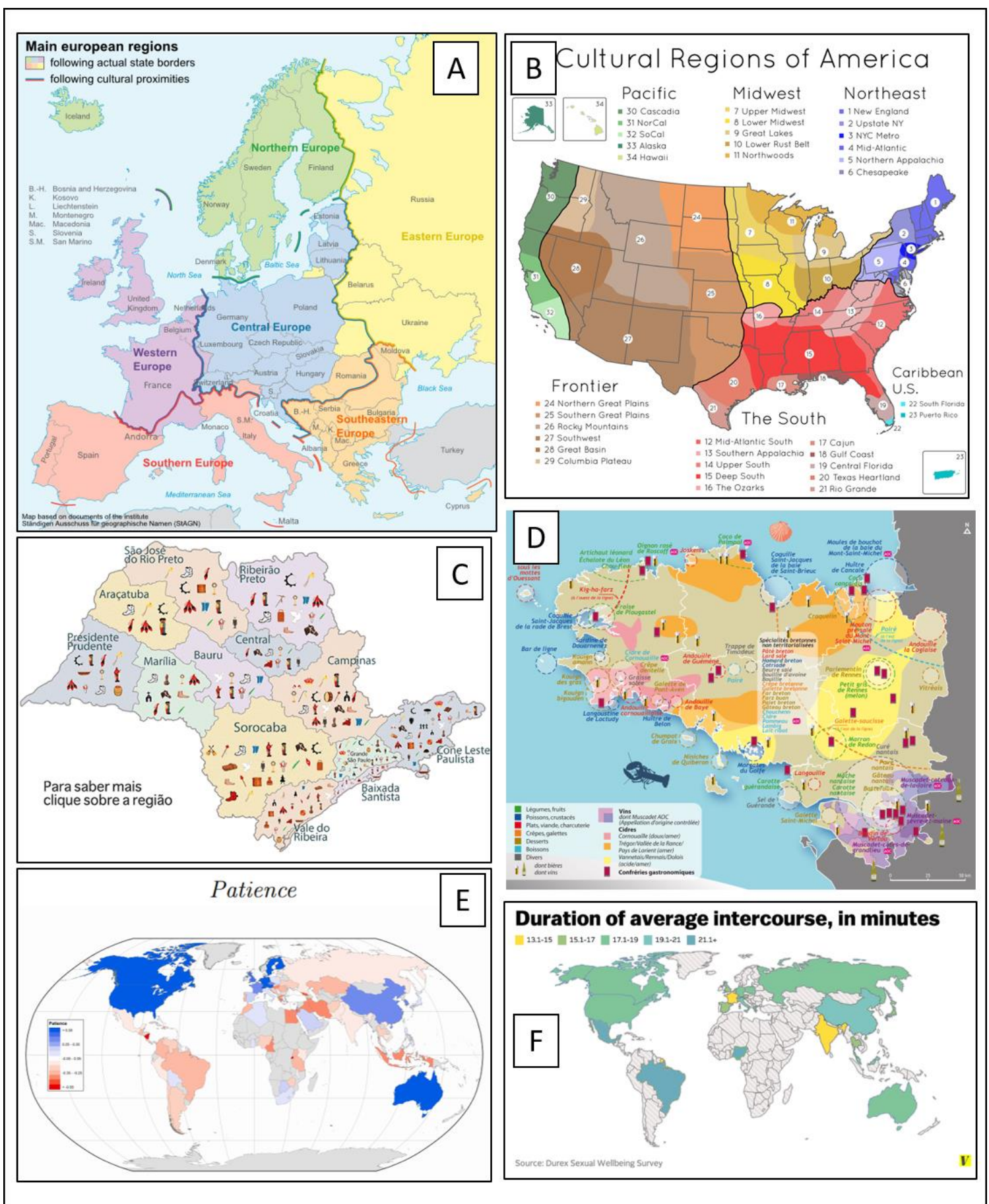

Observações: A - Principais regiões europeias por bordas estatais e afinidade cultural (baseado em documentos do Instituto Standigen Ausschuss für geographische Namen (SIAGN)); B - Regiões culturais norte americanas; C - Patrimônio cultural imaterial de São Paulo. (Abaçaí Cultura e Arte. 2019); D - Patrimônio alimentar. Segredos da gastronomia bretã. (Bodlore-Penlaez M. \& Kervella D., Atlas de Bretagne / Atlas Breizh, Coop Breizh, 2011, p. 60). E - Mapa mundial de preferências: paciência. Baseado em 80 mil questionários respondidos em 72 países; $\mathbf{F}$ - Duração média de uma relação sexual, em minutos - (pesquisa patrocinada pela fábrica de preservativos Durex baseadas nas pesquisas Sexual Wellbeing Survey (2007/2008) e Face of Global Sex (2012). 
Figura 4 - Mosaico de representações cartográficas que abordam temáticas culturais de elevado grau de especificidade focadas no indivíduo.

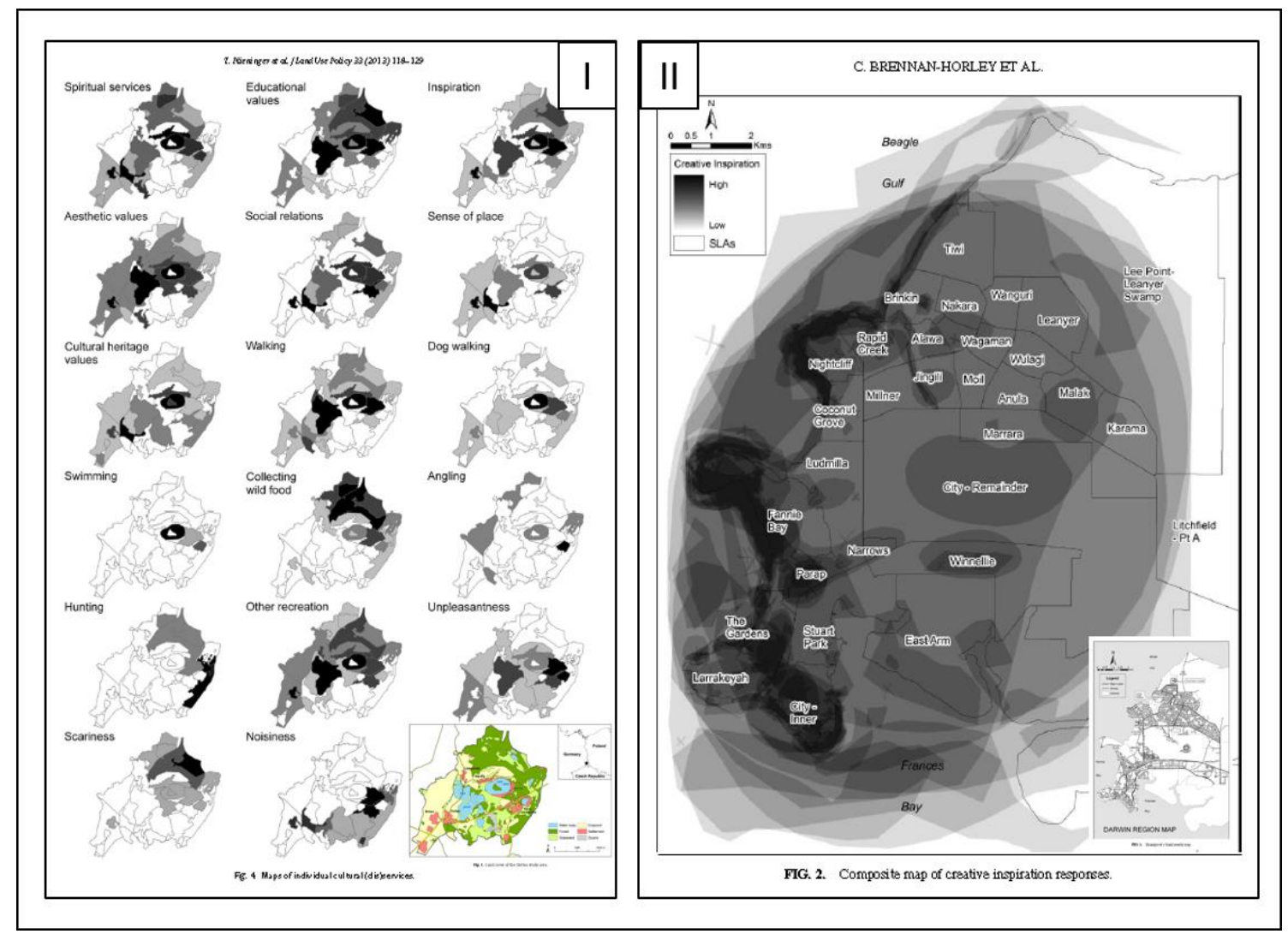

Fonte: BRENNAN-HORLEY et al, 2010; PLIENINGER, 2013 (representações adaptadas).

Observações: I - Mapas sintéticos sobre a percepção utilitarista da paisagem para usos culturais (PLIENINGER, 2013). O estudo realizou, em 2012, um mapeamento participativo espacialmente explícito da gama completa de serviços ecossistêmicos culturais percebidos por 93 pessoas que vivem em uma paisagem cultural na Alemanha Oriental. Os entrevistados foram convidados a distinguir locais no mapa que são frequentados ou evitados em determinadas situações, podendo indicar três áreas para cada situação. O estudo abrangeu aspectos como "paisagens com valor educacional ou espiritual", e ainda, locais favoráveis para "natação, coleta de alimentos nativos, caça" e até "paisagens desagradáveis". II - Inspiração criativa (BRENNAN-HORLEY et al, 2010). O objetivo deste mapa é mostrar a aplicabilidade dos Sistemas de Informações Geográficas às metodologias etnográficas. Em termos simples, foi solicitado a 98 indivíduos cuja profissão tem nexo com aspectos criativos que elaborassem mapas mentais indicando os locais de maior inspiração na cidade de Darwin, Austrália. Esses mapas foram georreferenciados e os dados foram interpolados para identificar zonas de maior inspiração criativa.

\section{CULTURA COMO IMAGINAÇÃO COLETIVA}

Bennedict Anderson (2008) assim diz, defendendo a ideia de que a nação é uma comunidade imaginada: "Ela é imaginada porque mesmo os membros da mais minúscula das nações jamais conhecerão, encontrarão ou nem sequer ouvirão falar da maioria de seus companheiros, embora todos tenham em mente a imagem viva da comunhão entre eles" (ANDERSON, 2008, p.32). 0 autor desenvolve ainda a ideia de que "qualquer comunidade maior do que a aldeia primordial do contato face a face (e talvez mesmo ela) é imaginada" (ANDERSON, 2008, p.33). Propõe-se uma dimensão semelhante para a cultura: uma imaginação coletiva.

As memórias coletivas descritas por Halbwachs (1990) permitem o desfrute do sentimento de pertencimento de grupo e, ao mesmo tempo, contribuem para a evocação e manutenção das lembranças impessoais. O significado das experiências coletivas, por sua vez, pode repousar em dimensões semelhantes da percepção e do entendimento, o que é explicado pelo confronto dialético com as experiências individuais. Dada à excepcionalidade da trajetória das experiências individuais, as experiências coletivas são vivenciadas a partir de distintas emoções, crenças e 
racionalizações. Generaliza-se, por intermédio de aproximações, aquilo que seja cultura. Os seus pilares constituintes, muitas vezes repetidos, passam a ser entendidos como descritores de uma entidade tangível, quando, na verdade, não passam de arquétipos miseráveis se comparados à pluralidade identitária. Assim, a cultura, bem como categorias sacrossantas das humanidades tais como nação ou raça, funcionam melhor como crenças coletivas do que como entidades tangíveis.

Claramente, para chegar a este entendimento, não é possível trazer a tiracolo pressupostos tradicionais que balizam o conceito de cultura, como, por exemplo, a ideia de uma entidade rígida, monolítica, que reage por meio de subtrações ou adições diacrônicas e que não seria capaz, por exemplo, de se hibridizar espaço-temporalmente. A mera pretensão da cultura de se portar como detentora de variáveis sociais implacáveis que atingem os indivíduos que a portam de forma homogênea apresenta-se antagônica à ideia aqui defendida.

Os elementos constituintes da cultura podem ainda ter efeitos que atuam, no âmbito da individualidade ou da coletividade, de forma mais ativa ou passiva. As diferenças entre a atividade ou passividade destes efeitos também não podem ser entendidas em dois extremos. Há de se perceber, por exemplo, que os dogmas religiosos possuem efeitos mais passivos do que a culinária. Em termos práticos, alguns comportamentos passivos podem encontrar fundamentação em dogmas religiosos ainda que o indivíduo não reconheça a origem destes fundamentos.

Propõe-se que a cultura é uma imaginação coletiva detentora de um conjunto estereotipado de elementos. Nesse sentido, não se está negando a existência da cultura, mas se afirmando que a pretensão de determinação de sua totalidade é mítica, o que é explicado, por sua vez, pela natureza intersubjetiva de sua delimitação (tanto em sua descrição como em seu alcance espacial). Vivendo como entidade mítica, a cultura e os elementos que são reconhecidos como integrantes do seu corpo intangível, atuam dialética e permanentemente no cotidiano dos indivíduos, produzindo, contudo, efeitos muito distintos. Esses elementos identificados como componentes da cultura passam a ser tão reconhecidos que são repetidos em verso e prosa, ainda que não façam parte de experiências essencialmente ligadas ao convívio cotidiano de uma parcela importante de pessoas que os reconhece.

\section{MAPAS MENTAIS}

Os mapas mentais são elaborações que se tratam de imagens espaciais que as pessoas têm de lugares conhecidos, direta ou indiretamente. Tem sido utilizado como ferramentas de pesquisa desde os anos 1960, conjuntamente à ascensão da Geografia Behaviorista (Brennan-Horley et.al, 2010), que teve na obra Place and Placelessness de Edward Relph (1976) um dos seus textos seminais. Os mapas mentais são construídos por intermédio de um filtro mental e da codificação de dados sensoriais, sendo, portanto, subjetivos, privativos e únicos (GRAHAM, 1976). As representações espaciais podem abordar o espaço vivido do cotidiano ou mesmo de localidades espaciais distantes, imaginadas somente pela divulgação dos meios de comunicação (ARCHELA et al., 2004). As impressões pessoais, que marcam as elaborações cartográficas mentais, muitas vezes são marcadas por distorções quando a mesma área é elaborada por indivíduos diferentes (ou quando as produções são feitas em diferentes estágios da vida ou em diferentes momentos emocionais) (WATERMAN e GORDON, 1984). Jean-Claude Muller (1985) considera que estas distorções são esperadas pelo fato de as pessoas não lembrarem os valores de latitude e longitude dos lugares, baseando a distribuição de elementos no posicionamento relativo. Destaca ainda que "estudos cartográficos cognitivos mostram que as pessoas possuem uma visão egocêntrica do seu ambiente e alguma dificuldade em julgar direções" (MULLER, 1985, p.51).

Os mapas mentais podem ser produzidos contemplando diferentes escalas geográficas, explorando os lugares e, até mesmo, apontando formas continentais. Neste último caso, a familiaridade com a leitura de mapas não-mentais tende a diminuir as distorções entre os mapas mentais e os mapas de projeções consagradas, como pode ser atestado por Sanders e Porter (1974). Estes autores compararam os mapas mentais de escala continental produzidos por estudantes tanzanianos e norte-americanos sobre o continente africano. Mais familiarizados com o continente que abriga o seu país, estudantes tanzanianos produziram mapas mentais da África com detalhes mais ricos nos recortes litorâneos. Pocock (1979) endossa o argumento ao considerar que a familiaridade com a área é uma chave para a sofisticação cartográfica. O autor destaca, por outro lado, que a 
familiaridade não é uma variável que interfere na escolha estilística da representação (POCOCK, 1976).

As distorções na percepção da posição geográfica relativa representam mais do que anomalias curiosas. Para Muller, estas distorções ocorridas em mapas mentais de escala global revelam a estrutura mental na representação da informação geográfica, que estaria, por sua vez, fortemente ligada à geopolítica (Muller, 1985).

Roger M. Downs (1981) (sem abordar especificamente os mapas mentais e em um argumento que se encaixa perfeitamente para os mesmos) acredita que os mapas podem ser vistos/compreendidos de duas formas. Por um lado, os mapas representam o mundo na nossa mente, pela natureza das representações internas do espaço e até mesmo pela própria estrutura no conhecimento que nos guia. Por outro, os mapas representam o mundo real para o mundo consensual que se presume observá-lo.

Os mapas mentais são, muitas vezes, produzidos a partir da visão do autor sobre uma dada porção do espaço. Permitem, portanto, que se adentre nos referenciais espaciais construídos pelo seu autor, que incluem, eventualmente, hierofanias. Por outro lado, como instrumento da Geografia Cultural, tem se multiplicado os mapeamentos produzidos a partir de impressões coletivas acerca dos fatos culturais. Foi o que Shobe e Banis (2010) fizeram ao trabalhar com alunos das disciplinas Geografia da Cultura Popular e Geografia Cultural do programa de mestrado de uma universidade americana. Os autores produziram um mapeamento sobre as regiões musicais norte-americanas quantificando a percepção dos alunos e identificando áreas mais associadas a determinados estilos musicais. Há mais de 50 anos, Gould e White (1968), em seu trabalho, mapearam na ilha da GrãBretanha as áreas mais desejadas como local de moradia para estudantes que deixavam o Ensino Básico. Os mapeamentos foram produzidos a partir de médias numéricas. Vários mapas foram produzidos a partir da percepção de estudantes de diferentes localidades da ilha da Grã-Bretanha, mostrando a variação da valorização do espaço na percepção dos indivíduos. Em tese, elaborações similares podem ter como alvo elementos topofílicos/topofóbicos. Como diferença, esses mapas mentais representam a coletividade, ainda que o método de execução e de aglutinação dos dados tenha sido escolhidos por um organizador/pesquisador/cartógrafo.

Como visto, existe uma pluralidade de mapas mentais que procurar-se-á, sinteticamente, dimensionar. Os mapas mentais apresentam-se:

- Em múltiplas escalas, podendo contemplar em um dos extremos, a rua, e em outro, toda a Terra;

- Em múltiplos temas, podendo contemplar aspectos referentes a percursos, servindo como um guia de localização, e, em outro âmbito, servindo a abordar impressões culturais;

- Diversos quanto aos sujeitos, podendo referir-se a uma produção que reflete uma experiência individual, a do autor, e, em outro âmbito, referir-se à coletividade, como nos mostra as experiências de Shobe e Banis (2010) e Gould e White (1968);

- Em múltiplos métodos de representação, sendo que alguns podem ter mais apreço com a formalidade cartográfica e outros completamente desprovidos de qualquer tipo de compromisso com escalas, coordenadas geográficas e, até mesmo, orientação; podem também ser construídos em diferentes ângulos de observação;

- Em distintas temporalidades, podendo se referir às lembranças de tempos pretéritos.

A partir deste desenvolvimento, pode-se então abordar uma das perguntas norteadoras deste artigo: Os mapas mentais seriam exceções mediante a crítica às regionalizações culturais?

Sabe-se que os mapas mentais podem representar a cultura, nos seus mais variados graus de generalização ou especificidade (Quadro 1). Independentemente da construção do mapa mental centrar-se na tentativa de codificação de dados sensoriais (GRAHAM, 1976) pertencentes ao âmbito do indivíduo ou, como nos mostrou a experiência de Shobe e Banis (2010) e Gould e White (1968), da coletividade, a questão aqui é outra: se faz necessário estar focado na pretensão de totalidade do elemento cartografado. Desejar representar espacialmente a "cultura brasileira" ou a "cultura mineira" é um anseio totalizante que não condiz com os princípios da moderna 
antropologia: a cultura vista como uma entidade permeável, híbrida, heterogênea e dinâmica, o que sustentaria a inexequibilidade de sua delimitação.

Contudo, temas culturais de maior especificidade, como a avaliação da aprazibilidade das paisagens de regiões de uma dada área, testam o princípio da pretensão da totalidade. Se um mapa mental com este tema é elaborado e apresentado com a devida singularidade: "as belezas amazônicas segundo um autor qualquer", parte-se do pressuposto que a discordância é aceitável e que a cartografia oferecida é única. Os limites cartografados, neste último exemplo, seriam limites identitários. Ainda que as identidades sejam moldadas diacronicamente, a proposta cartográfica em questão retrata um momento específico da trajetória formativa da identidade. Por isso, parece adequada a colocação de data na construção cartográfica. Os mesmos cuidados devem ser feitos quando os temas de maior especificidade sejam cartografados a partir das impressões de diversos indivíduos. A pretensão da totalidade inviabiliza a colocação de limites.

Gould e White (1968) assim batizaram o seu artigo: "The mental maps of British school leavers". Os autores mostraram por intermédio do título do artigo que não havia a pretensão da totalidade. No entanto, o corpo do seu texto, sobretudo na parte que versa sobre o método, deixa claro que a sua construção é ainda mais singular: os autores especificam informações mais precisas sobre o perfil do estudante que serviu de base para a construção de uma sequência de mapas sobre o grau de "habitabilidade" dos diversos condados da Grã-Bretanha.

Afirma-se, portanto, que os temas culturais que representam preferências ou impressões, desde que não sejam apresentados de forma totalizante, são passíveis de serem delimitados. A cultura propriamente dita não é passível de ser avaliada entre o prisma da singularidade $\mathrm{x}$ totalidade. Essencialmente totalizante, os limites da cultura não são realizáveis. Ainda que se considere a cultura como imaginação coletiva, limites consensuais são impossíveis. Como vistos, nem mesmo os limites dos Estados podem ser entendidos com base para delimitação cultural (NEWMAN, 2006).

\section{CONSIDERAÇÕES FINAIS}

Por meio das reflexões impostas pelas questões tratadas neste artigo foram explorados os contrassensos da delimitação geográfica da cultura. Apoiados em princípios que norteiam a moderna antropologia, considerou-se que a cultura não é passível de ser delimitada. Isto se explica devido à suas características, tais como a permeabilidade, o dinamismo e o hibridismo que dão o tom de sua intangibilidade. Aliás, acredita-se que devido aos inúmeros contrassensos acerca dos seus elementos constituintes, a cultura é uma imaginação coletiva: sua existência seria explicada da mesma forma como a categoria "raça", que, apesar de abolida biologicamente, vive no imaginário coletivo sendo, inclusive, apropriada como instrumento de militância política. A representação da cultura também é problemática devido à dificuldade consensual quanto aos seus elementos constituintes, fato que independe da escala de análise.

Quando há reflexão sobre temas culturais e há perspectiva de uma maior ou menor especificidade temática (como aquela que opõe, em exemplo de extremos, a cultura propriamente dita e o gosto musical), não é possível escapar dos contrassensos que envolvem sua delimitação, pois a problemática se mantém independente da escala geográfica de abordagem ou opção temática. Tal problemática é garantida, como visto, pela intangibilidade e o contrassenso constituinte do elemento cartografado.

Os mapas mentais, pelo seu lado, podem abordar temáticas culturais dentre os mais diversos graus de especificidade/generalização. Já que são produzidos a partir de experiências individuais, poderiam os mapas mentais não serem atingidos pelos contrassensos que acometem 0 mapeamento da cultura?

Conclui-se que os mapas mentais se tornam livres de embaraços em sua representação quando não possuem a pretensão de totalidade. Ou seja, os mapas mentais devem se apresentar claramente como uma porção limitada da totalidade do fenômeno que se pretendeu representar, seja por meio do seu título ou legenda. Nestes elementos cartográficos deve estar clara a participação dos pressupostos fenomenológicos que pautaram sua construção, com a indicação que a representação se refere às impressões particulares ou de coletividades específicas. Assim, os mapas mentais não podem ser apresentados como "quadros da cultura", sejam em qualquer 
escala ou nível de especificidade temática. Afinal, a cultura é imaginativamente totalizante, sendo esta pretensão um dos empecilhos de sua representação.

\section{REFERÊNCIAS}

ANDERSON, Benedict. Comunidades Imaginadas. São Paulo: Companhia das Letras, 2008.

ARCHELA, Rosely Sampaio; GRATÃO, Lúcia Helena B; TROSTDORF, Maria A. S. O lugar dos mapas mentais na representação do lugar. Londrina: Geografia, Vol.13, №1, jan-jun, p.127-141, 2004.

BHABHA, Homi K. O local da cultura. Belo Horizonte: Editora UFMG, 2013.

BRENNAN-HORLEY, Chris et.al. GIS, Ethnography, and cultural research: Putting maps back into Ethnographic Mapping. The Information Society, Vol.26, №2, p.92-103, 2010. https://doi.org/10.1080/01972240903562712.

CLAVAL, Paul. A Geografia Cultural. Florianópolis: Ed.UFSC, 2001.

Epistemologia da Geografia. Florianópolis: Ed.UFSC, 2011.

CONRAD, Joseph. O Coração das Trevas. São Paulo: Abril, 2010.

DOWNS, Roger M. Maps and Metaphors. The professional Geographer, vol.33, no3, August, p.287-293, 1981. https://doi.org/10.1111/j.0033-0124.1981.00287.x .

EAGLETON, Terry. A ideia de cultura. São Paulo: Unesp, 2011.

FROMENTIN, Eugène. Le pays de la soif, 1820-1876. Óleo sobre tela, $103 \times 143,2 \mathrm{~cm}$. Musee d'Orsay, Paris.

GAST, John. O Progresso Americano. Washington, DC: Litografia em cores, $37,6 \times 49 \mathrm{~cm}$. Library of Congress Prints and Photographs Division, 1872. Disponível em www.loc.gov/pictures/item/97507547/ em 1 de novembro de 2018.

GOULD, P. R.; WHITE, R. R. The mental maps of British school leavers. Regional studies, Vol.2, no 2, p.161-182, 1968. https://doi.org/10.1080/09595236800185171.

GRAHAM, Elspeth. What is a mental map? The Royal Geographical Society, Vol.8, no 4, p.259262, 1976.

GUPTA, Akhil; FERGUNSON, James. Beyond "culture", space, identity, and the politics of $\begin{array}{llllll}\text { difference. Cultural } & \text { Anthropology, } & \text { Vol.7, } & \text { no1, } & \text { p.6-23, }\end{array}$ https://doi.org/10.1525/can.1992.7.1.02a00020.

HALL, Stuart. Pensando a diáspora: reflexões sobre a terra no exterior. (in) Sovik, Liv (org). Da diáspora: identidades e mediações culturais. Belo Horizonte: Editora UFMG, 2013.

HALBWACHS, Maurice. A Memória Coletiva. São Paulo: Editora Vértice, 1990.

HEFFERNAN, Michael J. The desert in French orientalist paiting during the nineteenth century. London: Landscape Research, 16:2, p.37-42, 1991. https://doi.org/10.1080/01426399108706338.

HUNTINGTON, Samuel. O Choque das Civilizações e a recomposição da Ordem Mundial. Rio de Janeiro: Objetiva, 1997.

MULLER, Jean-Claude. Mental Maps at a global scale. Cartographica, vol.22, no4, p.51-59, 1985. https://doi.org/10.3138/L601-Q58N-8241-82PR .

NEWMAN, David. Boundaries. (in) Agnew, John et.al. A companion to Political Geography. Malden: Blackwell publishing, 2006.

PLIENINGER, Tobias et al. Assessing, mapping, and quantifying cultural ecosystem services at community level. Land use policy, v. 33, p. 118-129, 2013. https://doi.org/10.1016/j.landusepol.2012.12.013. 
POCOCK, Douglas C. D. Some characteristics of Mental Maps: An empirical study. Transactions of the Institute of British Geographers, Vol.1, no 4, p.493-512, 1976. https://doi.org/10.2307/621905.

. The contribution of mental maps in perception studies. Geography, Vol.64, nํ4, November, p.279-287, 1979.

PORTEOUS, Douglas J. Smellscape. Progress in Human Geography, vol.9, Issue 3, p.356-378, 1985.

PORTEOUS, Douglas J.; MASTIN, Jane F. Soundscape. Journal of Architectural and Planning Research. Vol. 2, oㅡ 2, September, p.169-186, 1985. https://doi.org/10.1177/030913258500900303

RELPH, Edward. Place and Placelesness. London: Pion Limited, 1976, 156 p.

SAÏD, Edward W. Orientalismo: o Oriente como invenção do Ocidente. São Paulo: Companhia de Bolso, 2007.

Cultura e Imperialismo. São Paulo: Companhia de Bolso, 2011.

SANDERS, Ralph A; PORTER, Philip W. Shape in revealed mental maps. Annals of the association of American geographers. Vol. 64, №2, june, 258-267, 1974. https://doi.org/10.1111/j.1467-8306.1974.tb00975.x .

SHOBE, Hunter; BANIS, David. Music Regions and Mental Maps: Teaching Cultural Geography. Journal of Geography, vol.109, no2, p.87-96, 2010. https://doi.org/10.1080/00221341.2010.482160

SILVA, Leonardo Luiz Silveira da; COSTA, Alfredo. A inadequação das regionalizações culturais mediante os pressupostos do pós-colonialismo. Salvador: Geotextos, Vol.14, №1, julho, 2018, p.225-247, 2018. https://doi.org/10.9771/geo.v14i1.26462 .

TUAN, Yi-Fu. Images and Mental Maps. Annals of the Association of American Geographers. Vol.65, N.2, june, 1975a. https://doi.org/10.1111/i.1467-8306.1975.tb01031.x .

TUAN, Yi-Fu. Place: an Experiential Perspective. Geographical Review, v.65, no, p.151-165, 1975b. https://doi.org/10.2307/213970.

. The significance of the artifact. Geographical Review, v.70, №4, p.462-472, 1980a. https://doi.org/10.2307/214079. Difel, 1980b.

Topofilia: um estudo da percepção, atitudes e valores do meio ambiente. São Paulo:

Strangers and Strangeness. Geographical Review, v.76, №1, jan, p.10-19, 1986. https://doi.org/10.2307/214781.

Tuan, Yi-Fu. Paisagens do medo. São Paulo: editora Unesp, 2005.

WALLERSTEIN, Immanuel. O universalismo europeu: a retórica do poder. São Paulo: Boitempo, 2007.

WATERMAN, Stanley; GORDON, Dan. A quantitative-comparative approach to analysis of distortion in mental maps. Professional Geographer, vol.36, oㅜ, p.326-337, 1984. https://doi.org/10.1111/j.0033-0124.1984.00326.x .

Recebido em: 06/06/2019

Aceito para publicação em: 12/11/2019 